\title{
Editorial
}

\section{Psicologia Cultural da Educação}

\author{
Giuseppina MARSICO',2 (D) 0000-0002-8683-2814 \\ Maria Virgínia Machado DAZZANI² ID 0000-0001-5303-3576
}

A educação é uma intervenção proposital no desenvolvimento de jovens seres humanos no contexto mais amplo da orientação informal das crianças para a idade adulta. Em qualquer sociedade onde exista a escolaridade formal, essa é uma versão institucionalizada da intermediação na organização coletivo-cultural ordinária do desenvolvimento humano. Em termos de relação Cultural-Natural, a escolaridade formal pertence ao domínio do cultivo (Valsiner, 2014).

Essas duas frases acima já são suficientes para justificar a urgência de redefinir a psicologia educacional, tendo um foco cultural. Esta edição especial fornece os principais ativos de um novo quadro chamado Psicologia Cultural da Educação para pensar sobre os seres humanos educados em seus ambientes culturalmente organizados.

Estamos aqui diante de uma das questões cruciais na educação que são as universalidades e particularidades do empreendimento educacional.

De fato, a Psicologia Cultural da Educação tenta abordar tanto as perspectivas universais quanto a diversidade cultural das intervenções educativas. Ao fazê-lo e em consonância com a psicologia cultural contemporânea da Dinâmica Semiótica (Valsiner, 2014, 2021) assumimos, como ponto de partida, a noção de cultura como principal organizadora da relação homem-contexto. Segundo Gurlerce (2015, p. 459): "A cultura não é uma variável independente, dependente ou indexada, mas um rótulo de processo que se refere à organização sistêmica de diversos fenômenos psicológicos em um contexto sócio-histórico".

Como é possível que o que é local possa ser útil para um discurso generalizado sobre o funcionamento psicológico? A resposta é que o que é localmente específico é sempre uma instância de uma ordem sociocultural (Stam \& Ellis, 2015). Esta resposta aparentemente simples tem enormes consequências teóricas e metodológicas. A cultura é um mediador que regula a interação pessoa-mundo. Nesse sentido, todos os ambientes culturais são universalmente os mesmos, mesmo que os recursos mediacionais possam diferir significativamente de um para outro. Wertsch (2007) definiu a mediação cultural explícita e implícita que atua no contexto educacional. A mediação cultural explícita funciona no processo formal de ensino-aprendizagem enquanto a mediação implícita está presente naquelas situações cotidianas fora do sistema escolar onde os indivíduos estão simplesmente envolvidos em atividades nas quais não é imediatamente evidente o que está

$\nabla \nabla v$

1 Universidade de Salerno, Dipartimento di Scienze Umane, Filosofiche e della Formazione. Via Giovanni Paolo II, 134, 8408 Fisciano, SA, Italia. Correspondência para: G. MARSICO.E-mail: <pina.marsico@gmail.com>

2 Universidade Federal da Bahia, Instituto de Psicologia, Curso de Psicologia. Salvador, BA, Brasil. Apoio: Esta edição especial contou com o apoio da Capes PRINT e do CNPq (Projeto Universal).

$\boldsymbol{\nabla} \boldsymbol{\nabla} \boldsymbol{\nabla}$

Como citar este artigo

Marsico, G., \& Dazzani, M. Z. (2022). Psicologia Cultural da Educação. Estudos de Psicologia (Campinas), 39, e220003. https://doi. org/10.1590/1982-0275202239220003e 
sendo mediado ou para quais propósitos. No entanto, nessas situações, alguns elementos cruciais de nossas identidades e condutas culturalmente aprovadas são mediados. O foco em se tornar uma pessoa e um membro da sociedade através da educação é, portanto, um tema importante que atravessa essa questão especial.

\section{Educação e Cultura: um diálogo tenso, mas necessário}

A educação foi provocativamente definida por Valsiner (2008) como uma "violência benevolente" no nível individual e coletivo. Idealmente, a educação significa proporcionar a melhor condição para a pessoa e para a comunidade. No entanto, qualquer intervenção educacional sempre tem um componente inerentemente tensionado, pois se, por um lado, pretende-se fornecer condições para ir além da informação dada, cultivar possibilidades e novos mundos possíveis (Bruner, 1996), por outro, desafia formas coletivas e pessoais de viver impondo o que é considerado a melhor prática educacional e cultural, num tempo e espaço específicos.

Aderimos à ideia de que a educação não é benéfica nem prejudicial a si mesma, mas é uma arena interessante para investigar o enigma do funcionamento psicológico e dos processos de desenvolvimento dentro de um ambiente sociocultural particular (Coppola et al., 2015; Marsico et al., 2015).

Nesse quadro, a Psicologia Cultural da Educação foca na conceituação "ontogenética" da educação, promovendo uma ideia de educação localizada sobre a liminar entre o que já está adquirido e o que está por vir (Marsico, 2017, 2018). A educação é a fronteira externa do desenvolvimento humano e o horizonte de avanço futuro na trajetória psicológica. Esse foco ontogenético na educação está em oposição direta à concepção ontológica desenfreada da educação que tem sido apoiada pela abordagem neoliberista em todo o mundo (Szulevicz et al., 2016) que está mais interessada na certificação, padronização e homogeneização dos produtos educacionais do que no aspecto de desenvolvimento que implica no processo ensino-aprendizagem, bem como nos ambientes educacionais informais.

Esta edição especial pretende contribuir para a discussão sobre educação do ponto de vista cultural, promovendo a reflexão sobre processos psicossociais relevantes, sistemas de valor, práticas e ideologias em atuação nos ambientes educacionais. Essa polifonia de perspectivas produz um diálogo tenso (Hviid \& Märtsin, 2019) que é considerado o tema central a ser investigado na perspectiva da Psicologia Cultural da Educação.

Esta edição especial proporcionará aos leitores uma jornada intelectual refrescante que inclui contribuições do Brasil, Canadá, Dinamarca, Noruega, Itália e China para iluminar a construção de uma educação culturalmente responsável e a cultivação educacional de vidas pessoais.

\section{References}

Bruner, J. S. (1996). The culture of education. Harvard University Press.

Coppola, C., Mollo, M., \& Pacelli, T. (2015). The development of logical tools through socially constructed and culturally situated activities. In G. Marsico, M. V. Dazzani, M. Ristum, \& A. C. Bastos (Eds.), Educational contexts and borders through a cultural lens. Springer. https://doi.org/10.1007/978-3-319-18765-5.

Gurlerce, A. (2015). The " $\&$ " has emerged. Seeking "culture" and "psychology" for Culture \& Psychology. Culture \& Pychology, 21(4), 455-468. https://doi.org/10.1177/1354067X15615800

Hviid, P., \& Märtsin, M. (2019). Culture in Education and Education in Culture: tensioned dialogues and creative constructions (Cultural Psychology of Education Book 10). Springer.

Marsico, G. (2017). Jerome S. Bruner: manifesto for the future of Education. Journal for the Study of Education and Development, 40(4), 754-781. https://doi.org/10.1080/02103702.2017.1367597.

Marsico, G. (2018). The challenges of the Schooling from Cultural Psychology of Education. Integrative Psychological and Behavioural Sciences, 52(3), 474-489. https://doi.org/10.1007/s12124-018-9454-6. 
Marsico, G., Dazzani, V., Ristum, M., \& Bastos, A. C. (2015). Educational contexts and borders through a cultural lens: looking inside (Cultural Psychology of Education 1). Springer.

Stam, H. J., \& Ellis, B. D. (2015). Cultural dope and "psychological dope": the ethnomethodological attitude and cultural psychology. Culture \& Pychology, 21(4), 469-476. https://doi.org/10.1177/1354067X15615810

Szulevicz, T., May Eckerdal, R., Marsico, G., \& Valsiner, J. (2016). When disruptive behaviour meets outcome-based education. Psihologija, 49(4), 447-468. https://doi.org/10.2298/PSI1604447S

Valsiner, J. (2008). Open intransitivity circles in development and education: pathway to synthesis. European Journal of Psychology of Education, 23(131), 131-147. https://doi.org/10.1007/BF03172741.

Valsiner, J. (2014). An Invitation to Cultural Psychology. Sage.

Valsiner, J. (2021). General Human Psychology. Springer.

Wertsch, J. V. (2007). Mediation. In H. Daniels, M. Cole, \& J. V. Wertsch (Eds.), The Cambridge companion to Vygotsky (pp. 178-192). Cambridge University Press. 